\title{
Collaboratively Understanding and Improving Outcomes for the Mother, Fetus, and Infant
}

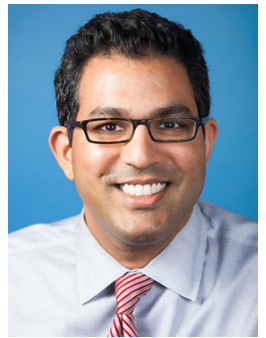

Ravi Mangal Patel, MD, MSc

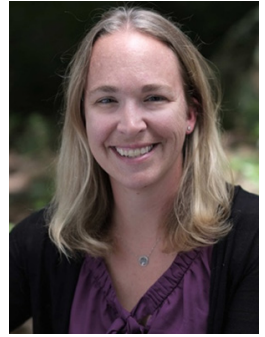

Tracy A. Manuck, MD, MS

Editors

Birth is an incredibly exciting and yet potentially dangerous period for a woman and her fetus, who attempts to navigate the complex transition to neonatal life. Many events during this period establish or disrupt long-lasting health for both the mother and her infant. The challenges during this period are too numerous to quantify, but yield opportunities for prevention and treatment strategies to improve perinatal care and neonatal outcomes. In this issue of Clinics of Perinatology, we highlight these opportunities by including articles that span across obstetrics and neonatology. We believe coordinated efforts across the spectrum of care are essential to yield the best possible outcomes. Toward that goal, Tracy A. Manuck and colleagues' article, "Quality Improvement in Perinatal Medicine and Translation of Preterm Birth Research Findings into Clinical Care," and Vidya V. Pai and colleagues' article, "Improving Uptake of Key Perinatal Interventions Using Statewide Quality Collaboratives," provide a context for improving perinatal care, with a focus on quality improvement and coordinated efforts by statewide collaboratives that have had marked success in improving perinatal care. ${ }^{1}$ Several topics provide the latest guidance and considerations on the "personalization" of common perinatal interventions, including the use of antenatal corticosteroids (See Whitney A. Booker and Cynthia Gyamfi-Bannerman's article, "Antenatal Corticosteroids: Who Should We Be Treating?"), methods of delivery (See Kate F. Walker and Jim G. Thornton's article, "Delivery at Term: When, How, and Why"), care of infants with specific birth defects (See Elizabeth K. Sewell and Sarah Keene's article, "Perinatal Care of Infants with Congenital Birth Defects"), and counseling at periviable gestational ages (See Matthew A. Rysavy's article, "Prognosis as an Intervention"). We also discuss optimization of commonly used or highly effective neonatal therapies started in the early postnatal period, including therapeutic 
hypothermia (See Girija Natarjan and colleagues' article, “Therapeutic Hypothermia: How Can We Optimize This Therapy to Further Improve Outcomes"), continuous positive airway pressure (See Clyde J. Wright and colleagues' article, "Continuous Positive Airway Pressure Failure: Evidence-Based and Physiologically Sound Practices from Delivery Room to the Neonatal Intensive Care Unit"), caffeine therapy (See Mitali Atul Pakvasa and colleagues' article, "Optimizing Caffeine Use and Risk of Bronchopulmonary Dysplasia in Preterm Infants: A Systematic Review, Meta-analysis and Application of Grading of Recommendations Assessment, Development, and Evaluation Methodology"), and oxygen administration (See Vishal Kapadia and Myra H. Wyckoff's article, "Oxygen Therapy in the Delivery Room: What Is the Right Dose?"). Our series also touches on perinatal infections, including new threats by Zika virus (See Amber M. Wood and Brenna L. Hughes' article, "Detection and Prevention of Perinatal Infection: Cytomegalovirus and ZIKA Virus") and established threats by HIV (See Leilah Zahedi-Spung and Martina L. Badell's article, "Current Strategies to Prevent Maternal-to-Child Transmission of Human Immunodeficiency Virus"). The perinatal period also sets in motion critical events shaping an infant's gut and brain health, and two articles review the latest on the maternal-infant microbiome (See Gregory Valentine and colleagues' article, "Relationship Between Perinatal Interventions, Maternal-Infant Microbiome and Neonatal Outcomes") and perinatal brain injury (See Christopher M. Novak and colleagues' article, "Perinatal Brain Injury: Mechanisms, Prevention and Outcomes").

We hope the readers of Clinics in Perinatology find these topics timely and of interest. We would like to thank and acknowledge the contributions of pediatricians, neonatologists, obstetricians, and maternal-fetal medicine specialists who have provided their expertise to guide perinatal interventions to improve neonatal outcomes.

Ravi Mangal Patel, MD, MSc

Division of Neonatology

Emory University School of Medicine and

Children's Healthcare of Atlanta

2015 Uppergate Drive Northeast, 3rd Floor Atlanta, GA 30322, USA

Tracy A. Manuck, MD, MS University of North Carolina-Chapel Hill Division of Maternal Fetal Medicine UNC Prematurity Prevention Program 3010 Old Clinic Building CB\#7516 Chapel Hill, NC 27599-7516, USA

E-mail addresses: rmpatel@emory.edu (R.M. Patel) tmanuck@med.unc.edu (T.A. Manuck)

\section{REFERENCE}

1. Wirtschafter DD, Danielsen BH, Main EK, et al, California Perinatal Quality Care Collaborative. Promoting antenatal steroid use for fetal maturation: results from the California Perinatal Quality Care Collaborative. J Pediatr 2006;148(5):606-12. 